Macedonian Pharmaceutical Bulletin, 66 (Suppl 1) 59 - 60 (2020)

Online ISSN 1857 - 8969

UDC: $615.2 .012: 001.895$

DOI: 10.33320/maced.pharm.bull.2020.66.03.029

Short communication

\title{
Innovative medicines \& managed entry agreements; a happy marriage?
}

\author{
Tanja Fens ${ }^{1,2}$, Maarten J. Postma $a^{1,2,3} *$ \\ ${ }^{I}$ Department of Health Sciences, University of Groningen, University Medical Center \\ Groningen, Groningen, The Netherlands \\ ${ }^{2}$ Institute of Science in Healthy Aging \& healthcare (SHARE), University of Groningen, \\ University Medical Center Groningen, Groningen, The Netherlands \\ ${ }^{3}$ Department of Economics, Econometrics \& Finance, University of Groningen, \\ Faculty of Economics \& Business, Groningen, The Netherlands
}

\section{Access to innovative medicines}

One current bottleneck concerns the access and reimbursement of innovative medicines, related to uncertainty about effectiveness and safety, but primarily conceived high prices. Moreover, there is an unmet medical and societal need for access of innovative medicines in the developing countries (Inotai and Kaló, 2019). Contemporaneous, all parties involved in the medicine pathway are facing their own challenges. Common ground to overcome the differences and fulfill the needs of all participants in one integrated healthcare system may be the design of Managed Entry Agreements (MEAs).

\section{Managed Entry Agreements}

A MEA is an innovative tool engaging health authorities and pharma-industry to reach agreements towards facilitating the access to innovative medicines and structure price negotiations as well. Using various instruments, MEAs often ensure minimalization of uncertainty from economic evaluations and budget impact analyses accounting for the real-world evidence (RWE) (Ferrario et al., 2017; Kanavos et al., 2017). Notably, the recent decade has shown a strong trend of including RWE in the assessments, next to obviously still the data from trials. Furthermore, there is fast change and wide range of reimbursement policies across Europe. In conjunction with conventional HTA, national authorities are using various contracting schemes, such as price cuts, reference price policies, budget caps, patient co-payments, payment by result, coverage with evidence development, price-volume agreements, discount agreements, agreements for free doses, payback agreements and conditional reimbursement (Wenzl and Chapman, 2019). Notably, all these contracts exemplify MEAs.

Types of MEA

MEAs can be financial- or health outcome-based agreements. The latter might be based on performance or evidence development. Financial agreements are increasing the financial certainty through price based on volume or market share, total spend, or a combination of both at population level, free treatments and fixed price or cost-sharing at the patient level. Health outcome-based agreements are supposed to cope with the uncertainty in the outcomes with risk-sharing, can be related to

\footnotetext{
*m.j.postma@rug.nl
} 
adherence, cover performance payment at population level or additional patient services and ensure shared accountability or evidence-based outcomes at the patient level. Finally, a third type of MEAs exist, sharing characteristics of both types previously mentioned. (Wenzl and Chapman, 2019)

\section{MEA in practice}

Globally seen up to 2018, Europe is a leader with more than $60 \%$ of MEAs submissions. Within Europe, Italy dominates with 88 innovative contracting submissions, followed by the UK (70), and Sweden (68). (Deloitte, 2019) When MEA-type is concerned, preferred use of financial-based agreements is noted in Belgium, Lithuania, England, Portugal, Malta, Cyprus, while the performancebased ones were more common in the Netherlands, Sweden and Czech Republic. (Kanavos et al., 2017)

The latter are concerned with coverage-underevidence-development. Notably, monitoring processes are not transparent and primarily focused on effectiveness, which demonstrates need for future attention on safety as well. Obviously, the field of MEAs is an extremely dynamic field, for example, the Netherlands recently moved away from performance to price negotiations. (Wenzl and Chapman, 2019) The utilization of MEAs in Central and Eastern Europe is mostly dominated by discounts $(73 \%)$, paybacks (14\%), price-volume agreements (5\%), free doses, and bundle agreements $(<5 \%)$. (Ferrario et al., 2017) These agreements are mainly focusing on oncology and diabetes medicines. Even though the implementation and utilization trend is increasing, there is a lack of transparency noted in these countries. (Ferrario et al., 2017; Inotai and Kaló, 2019).

\section{Future implications \& conclusion}

Access to innovative medicines, personalized treatments and improved medicine performance, affordability within the budget and effectiveness uncertainty, as well as impetus for further research into innovative medicines, all reflect advantages justifying the use of MEAs. Yet, further work on MEAs is required. Notably, further development in the area of transparency in pricing and costing are needed as well as solutions for medicine access after agreement expiration, simplifying and setting a standard agreement framework, improved patient and data monitoring mechanisms with attention on safety outcomes, sharing information from performance-based MEAs and developing methodologies towards measuring societal value for continues use of gathered data in HTA. (Kanavos et al., 2017; Wenzl and Chapman, 2019)

In conclusion, increased and systematic use of HTA in correlation with MEA facilitates the access to innovative medicines and represents a good informative tool for the decision makers.

\section{References}

Deloitte, L.L.P., 2019. Patient access to inovative medicines in Europe, A collaborative and value based approach, January 2019. Available at: https://www2.deloitte.com/content/dam/Deloitte/cz/D ocuments/legal/deloitte-uk-patient-access-toinnovative-medicine-in-europe.pdf.

Ferrario, A., Arāja, D., Bochenek, T., Čatić, T., Dankó, D., Dimitrova, M., Fürst, J., Greičiūtè-Kuprijanov, I., Hoxha, I., Jakupi, A., Laidmäe, E., Löblová, O., Mardare, I., Markovic-Pekovic, V., Meshkov, D., Novakovic, T., Petrova, G., Pomorski, M., Tomek, D., Voncina, L., Haycox, A., Kanavos, P., Vella Bonanno, P., Godman, B., 2017. The implementation of managed entry agreements in Central and Eastern Europe: Findings and Implications. Pharmacoeconomics 35, 1271-1285. Available at: https://doi.org/10.1007/s40273-017-0559-4.

Inotai, A., Kaló, Z., 2019. How to solve financing gap to ensure patient access to patented pharmaceuticals in CEE countries? the good, the bad, and the ugly ways. Expert Review of Pharmacoeconomics \& Outcomes Research 19, 627-632. Available at: https://doi.org/10.1080/14737167.2019.1702524.

Kanavos, P., Ferrario, A., Tafuri, G., Siviero, P., 2017. Managing risk and uncertainty in health technology introduction: The role of managed Entry agreements. Global Policy 8, 84-92. Available at: https://doi.org/10.1111/1758-5899.12386.

Wenzl, M., Chapman, S., 2019. Performance-based managed entry agreements for new medicines in OECD countries and EU member states: How they work and possible improvements going forward. OECD Health Working Papers. Available at: https://doi.org/10.1787/6e5e4c0f-en. 